\title{
The evidence behind lung cancer screening: a narrative review of randomized clinical trials
}

\author{
Vincent J. Mase Jr ${ }^{1}$, Ulas Kumbasar ${ }^{2}$, Frank C. Detterbeck ${ }^{1}$ \\ ${ }^{1}$ Division of Thoracic Surgery, Yale University School of Medicine, New Haven, CT, USA; ${ }^{2}$ Department of Thoracic Surgery, Hacettepe University \\ School of Medicine, Ankara, Turkey \\ Contributions: (I) Conception and design: All authors; (II) Administrative support: None; (III) Provision of study materials or patients: None; (IV) \\ Collection and assembly of data: All authors; (V) Data analysis and interpretation: All authors; (VI) Manuscript writing: All authors; (VII) Final \\ approval of manuscript: All authors. \\ Correspondence to: Frank C. Detterbeck, MD. Division of Thoracic Surgery, Yale University School of Medicine, P.O. Box 208062, New Haven, CT \\ 06520-8062, USA. Email: Frank.detterbeck@yale.edu.
}

\begin{abstract}
Objective: This chapter serves as a narrative review of the randomized controlled trial (RCT) evidence demonstrating a reduction in lung cancer mortality with low-dose computed tomography (LDCT) and the interaction of aspects that contribute to an effective screening program.

Background: Lung cancer accounts for more deaths than breast, colon, and prostate cancer combinedcancers with mature screening programs, whereas lung cancer is typically advanced when detected.

Methods: A review of the literature on PubMed was conducted using the keywords related to lung cancer screening. A narrative review was compiled of the eight RCTs evaluating the efficacy of LDCT for lung cancer screening as well as subsequent publications related to these articles and guidelines.

Conclusions: Lung cancer screening by chest X-ray is not effective; however, two large, randomized control trials, National Lung Screening Trial (NLST) and Nederlands-Leuvens Longkanker Screenings Onderzoek (NELSON), have demonstrated a mortality benefit for LDCT in a defined high-risk population. United States eligibility criteria are healthy individuals age 50-80 years, with a $\geq 20$-pack-year smoking history, either current smokers or having quit $\leq 15$ years ago. LDCT is an effective tool for lung cancer screening. Implementation of screening is a complex interplay of many factors that influence the impact and efficiency. Furthermore, screening involves trade-offs that can be viewed from various perspectives.
\end{abstract}

Keywords: Lung cancer; non-small cell lung cancer; screening; chest CT; randomized trials

Received: 13 June 2021; Accepted: 23 July 2021; Published online: 30 August 2021.

doi: $10.21037 /$ ccts-21-30

View this article at: https://dx.doi.org/10.21037/ccts-21-30

\section{Introduction}

Lung cancer remains a major global health risk; any initiative that has incremental improvement will ultimately be impactful. Lung cancer accounts for more deaths than breast, colon, and prostate cancer combined-all of which have mature screening programs. Overall the lifetime risk of developing lung cancer is 1 in 15 for men and 1 in 17 for women (1). For active smokers the lifetime risk of developing lung cancer is 1 in 6 (2).

Advances in lung cancer have led to a multitude of treatment options for patients with all types and stages of lung cancer. Our understanding of lung cancer tumor biology has evolved tremendously over the past 10 years. There is a spectrum of aggressiveness, from life-threatening lung cancers that have been recognized for decades to profoundly indolent tumors that may never require treatment. Low-dose computed tomography (LDCT) screening identifies lung cancer at an earlier stage for which there are several local treatment options that are safe and effective. The overall 5 -year survival for Stage IA lung cancer is $\sim 70 \%$ (3).

A comprehensive screening program requires an 
PLCO: Lung Cancer Mortality

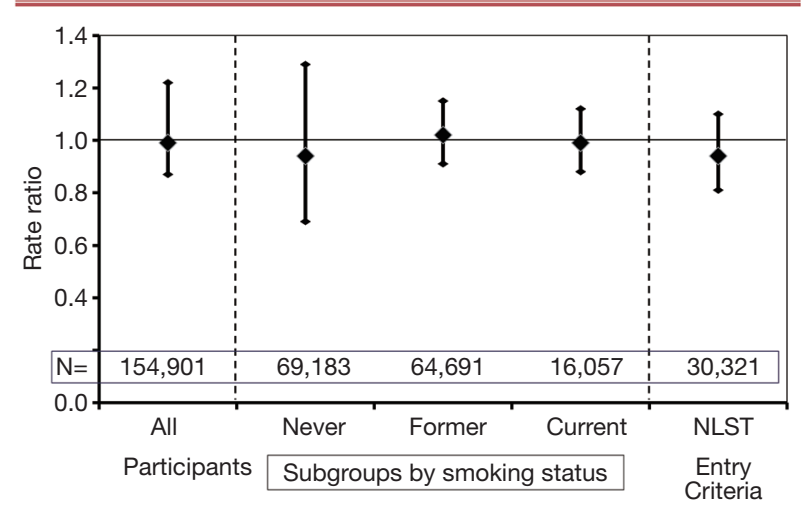

Figure 1 Results of the PLCO trial. Effect of screening for lung cancer by chest radiograph on lung cancer mortality in the PLCO screening trial. Data taken from Oken et al. (4). NLST, National Lung Screening Trial; PLCO, Prostate, Lung, Colon and Ovarian.

appreciation of screening limitations and must strike the right balance. Screening involves canvassing a healthy population; while these individuals are at-risk of developing a disease, the reality is that most will remain healthy. Screening has huge benefits for a few (lung cancer death averted) but has a low risk of harm to many. Targeting the right "at-risk" population necessitates understanding that casting a wider net impacts more patients but with a diminishing incremental benefit. Second, prevention of lung cancer by effective smoking cessation programs and public policy will always be better than screening. Third, screening only averts some lung cancer deaths; advances in treatment continue to be relevant. We present the following article in accordance with the Narrative Review reporting checklist (available at https://ccts.amegroups.com/article/ view/10.21037/ccts-21-30/rc).

\section{Methods}

An English language search of the literature on PubMed was conducted using the keywords related to lung cancer screening (lung cancer, non-small cell lung cancer, screening, early detection). We focused on randomized controlled trials (RCTs) of screening using either Chest radiographs or computed tomography (CT) imaging, as well as recent formal screening guidelines or statements by regulatory agencies. A narrative review was compiled of the eight RCTs evaluating the efficacy of LDCT for lung cancer screening.

\section{Results}

\section{Results of CXR as a screening test}

No mortality benefit ensues from lung cancer screening using either chest X-ray (CXR) or CXR plus sputum analysis. The most recent RCT to address this was the Prostate, Lung, Colorectal, and Ovarian Cancer Screening trial (PLCO, Figure 1) (4). No difference in lung cancer mortality was seen, regardless of the degree of smoking.

A common misconception among patients is to equate a CXR with CT, thinking that if they had a CXR there is no reason to get a screening CT. Patients sometimes ask to quantify the difference in a recent CXR they had compared to enrolling in a LDCT screening program for lung cancer. Current guidelines do not support substituting CXR as a screening tool for lung cancer.

CXR remains highly useful in investigating a symptom, such as a lingering cough. This constitutes using CXR as part of an evaluation, instead of as a screening tool in asymptomatic individuals.

\section{Results of screening using LDCT}

Several RCTs have evaluated the efficacy of LDCT. The two largest trials stand out: The National Lung Screening trial (NLST) (5) and the Nederlands-Leuvens Longkanker Screenings Onderzoek (NELSON) trial (6); these were adequately powered to detect a mortality benefit. The other studies were too small to independently address lung cancer mortality but add to an aggregate assessment (7-12) (Figure 2).

These trials have similarities but also differences in design, in the CT parameters, eligibility requirements and follow-up duration. This is summarized in Table 1 (5-12). An estimate of the overall risk for development of lung cancer can be gained by looking at the rate of development of lung cancer among trial participants. This ranges from $0.8 \%$ to $4.7 \%$ over the reported study duration.

\section{Reduction in lung cancer mortality}

The NLST and NELSON trials both found a dramatic and consistent benefit for lung cancer screening with LDCTapproximately $20 \%$ of lung cancer deaths were prevented $(5,6)$. There is no single intervention in the field of lung cancer that has such an impact. Note that while these trials used different controls (regular CXR or no screening), the mortality benefit was seen in both instances (furthermore the PLCO trial demonstrated no difference between CXR and no screening). The American College of Chest 


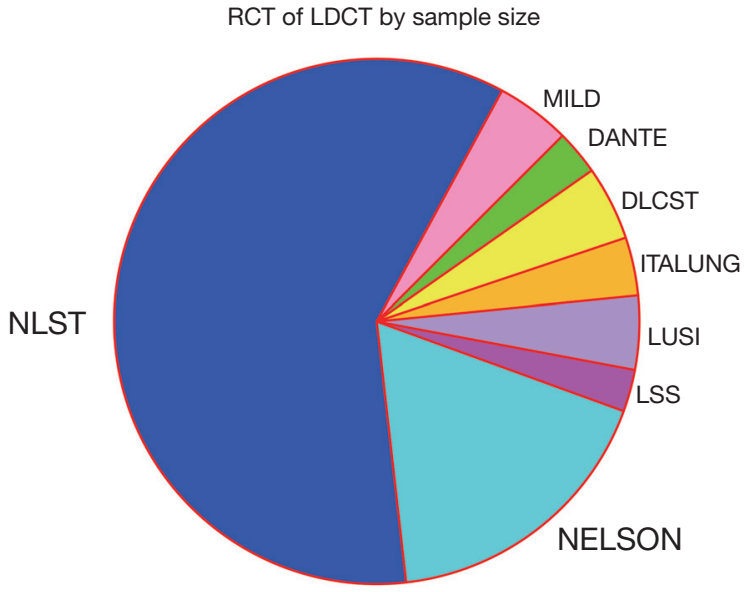

Figure 2 Relative size of major RCTs of LDCT screening for lung cancer. Number of participants in major lung cancer screening studies reporting mortality outcomes. Study names and references: DANTE: Detection and Screening of Early Lung Cancer by Novel Imaging Technology and Molecular Essays Trial (9); DLCST: Danish Lung Cancer Screening Trial (11); ITALUNG (8); LUSI: Lung Cancer Screening Intervention (12); LSS: Lung Screening Study (7); MILD: Multicentric Italian Lung Detection Trial (10); NLST: National Lung Screening Trial (5); NELSON: Nederlands-Leuvens Longkanker Screenings Onderzoek (6). LDCT, low-dose computed tomography; RCT, randomized controlled trial.

Physicians (CHEST) recently conducted a meta-analysis of LDCT screening, thus providing a recent aggregate of all the RCTs (Figure 3) (13). This also demonstrated an approximately $20 \%$ reduction in lung cancer deaths.

\section{Stage shift}

Both the NLST and the NELSON trials found a marked reduction in the number of patients with stage IV NSCLC in the screened arm vs. the controls (Figure 4) $(5,14)$. The reduction in higher stage tumors accounts for the mortality reduction. There is a corresponding increase in stage IA tumors, with relatively little difference in the number of patients with stage IB-IIIA tumors.

These studies also found a higher overall number of cancers in the screened arms (predominantly an excess of stage IA tumors). This reflects that screening inherently detects a contingent of indolent lung cancers. These are sometimes referred to as "over-diagnosed" cancers. However, the black-and-white term overdiagnosis is primarily useful to an epidemiologist looking retrospectively at what happened to a cohort (15). For clinicians who are prospectively managing individual patients, the key is to recognize that there is an increased proportion of indolent tumors, for which a more nuanced management approach is needed than in a non-screened population.

\section{Management of LDCT screening results}

LDCT is a sensitive test; small nodules are found commonly. In fact, most patients will have a nodule detected within a few years of screening. On the first scan about $20 \%$ of participants will have a nodule detected (Figure 5) (16). It is important to understand that such a finding is not a cause for concern. The term that is often used for such a finding is a "positive screening CT"- this term should be abandoned because it implies a likely lung cancer when the reality is that about $96-97 \%$ of these findings are only background noise. Additionally, screening programs have processes in place that effectively distinguish noise from a concerning lesion. A "finding worth mentioning" is perhaps a better term.

It is easy to play a numbers game by altering the definition of what is a finding worth mentioning. Raising the size threshold (e.g., from 4 to $6 \mathrm{~mm}$ ) quickly decreases the rate of such findings-but may affect the impact of the screening interval, compliance and mortality benefit. The NELSON study used a markedly different definition by only counting findings that were shown over time to be growing (indeterminate lesions being evaluated were set aside) (6). When the same definition of a CT finding is applied to the NELSON trial the baseline rate of these findings is $21 \%$, similar to other RCTs.

The RCTs have consistently shown a good ability to identify findings of little concern; only $\sim 2 \%$ of patients undergo a surgical biopsy procedure (including treatment of lung cancer) (17). On the other hand, $\sim 25 \%$ of these are for a benign nodule (i.e., $~ 0.5 \%$ of screened patients) (17). While the risk and discomfort of a video-assisted thoracoscopic surgery (VATS) wedge is low, a biopsy for a benign nodule must certainly be considered a downside of screening. A desire to lower this rate must consider the other side of the coin - a missed or delayed biopsy of a lung cancer.

Recognizing the need for a consistency, the American College of Radiology Imaging Network (ACRIN) developed a system of categorizing and reporting screening CT findings known as Lung Imaging Reporting and Data System (Lung-RADS) (18). This has been widely adopted. LungRADS uses $6 \mathrm{~mm}$ as the size threshold for a nodule to be "worth mentioning" on a baseline scan, and $4 \mathrm{~mm}$ for a new nodule on an annual incidence scan (LungRADS 
Table 1 Characteristics of major RCT of LDCT screening for lung cancer

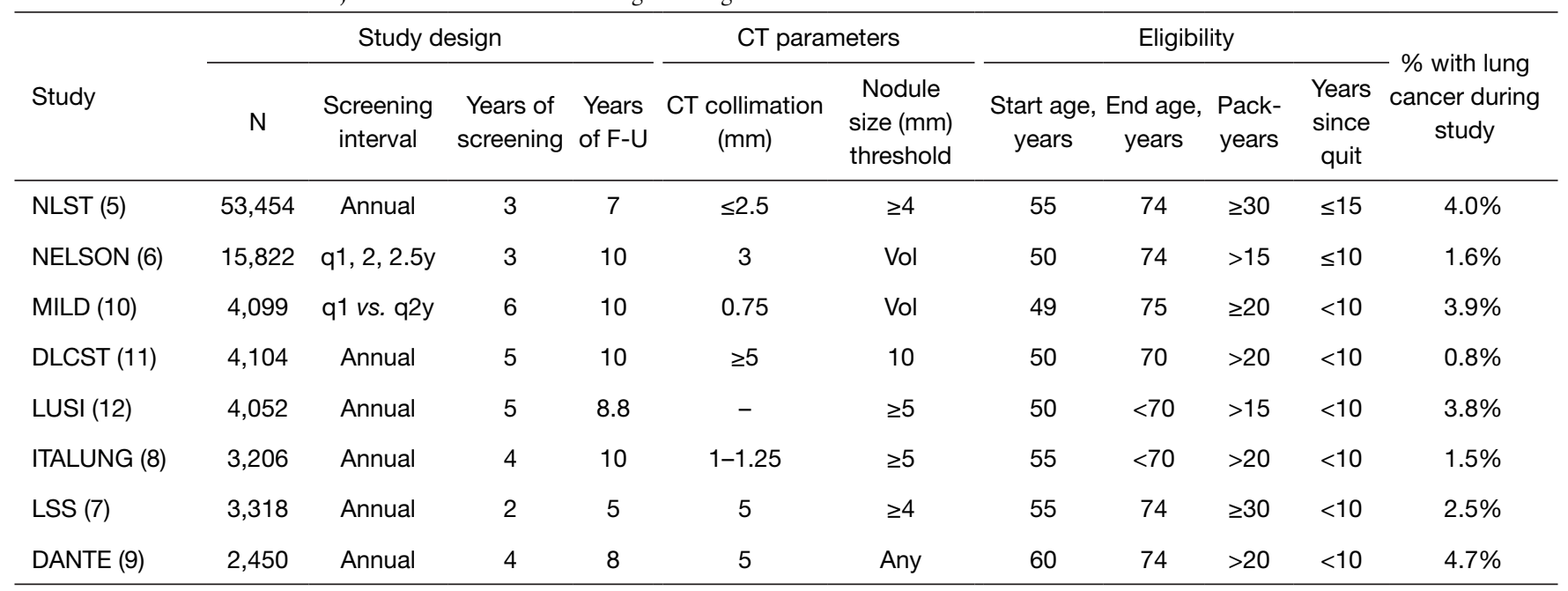

Inclusion criteria: RCTs of LDCT with $>1,000$ patients and reporting mortality outcome. DANTE, Detection and Screening of Early Lung Cancer by Novel Imaging Technology and Molecular Essays Trial; DLCST, Danish Lung Cancer Screening Trial; F-U, follow-up; LDCT, low-dose computed tomography; LUSI, lung cancer screening intervention; LSS, lung screening study; MILD, Multicentric Italian Lung Detection Trial; NLST, National Lung Screening Trial; NELSON, Nederlands-Leuvens Longkanker Screenings Onderzoek; RCT, randomized controlled trial; Vol, volumetric criteria; y, year.

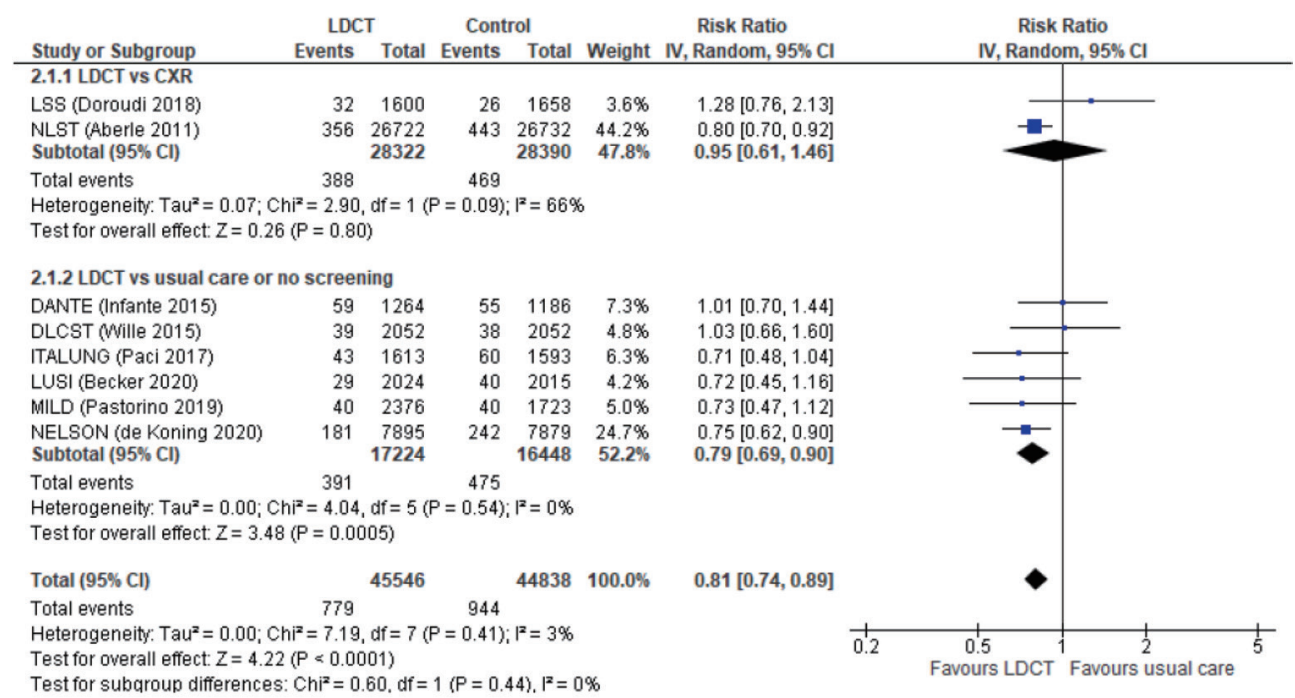

Figure 3 Meta-analysis of mortality benefit. Lung cancer mortality in randomized trials of LDCT screening. Reproduced with permission from Mazzone et al. (13). LDCT, low-dose computed tomography.

category 3).

\section{Managing an effective LDCT screening program}

Screening is a complex interplay of selection (a population with sufficient risk and few serious comorbidities), the sensitivity/specificity of the screening test, the interval between screening tests, the availability of effective treatment, the risk of complications or harms as a result of screening, and the degree with which the screened individuals comply with screening and treatment recommendations (17). The relationships of the factors are interconnected and non-linear. 


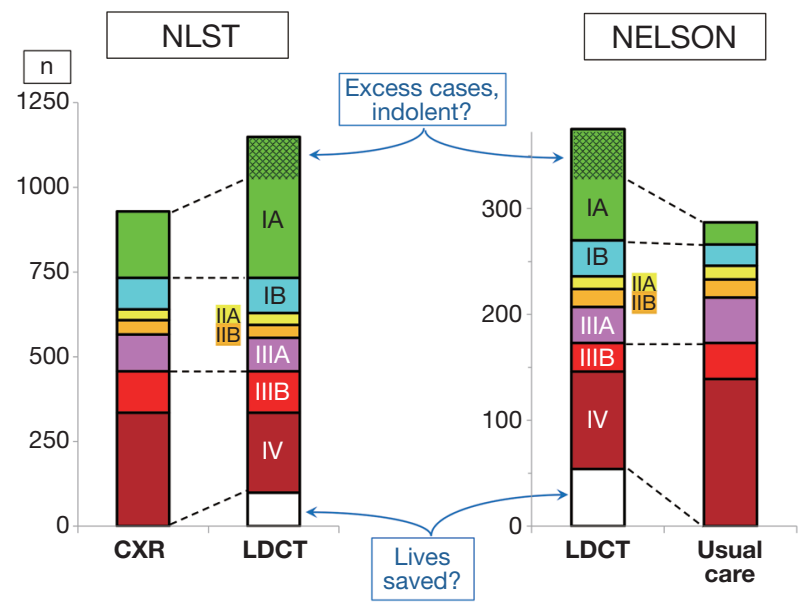

Figure 4 Stage shift. Proportion of lung cancers by stage in the NLST and NELSON trials $(5,14)$. NLST, National Lung Screening Trial; NELSON, Nederlands-Leuvens Longkanker Screenings Onderzoek; CXR, chest X-ray; LDCT, low-dose computed tomography.

A well-organized program is needed to optimize the benefits of screening.

Choosing the population to screen is a starting point. There is a balance between maximizing the number of deaths prevented and efficiency. Efficiency is maximized by screening a narrow very high-risk population. In the highest risk subgroup in the NLST, the number-needed-to-screen (NNS) to save a life was 82 (Figure 6A) $(19,20)$. On the other hand, casting a broad net has the benefit of preventing a greater number of lung cancer deaths. A large increase in the size of the net is needed to achieve an increasingly smaller increment in the number of lives saved (Figure $6 B$ ). Note that all screening participants are exposed to the low risk of harms of screening, whereas the benefits are experienced only by those that develop lung cancer (actually only the 20\% of those in whom death is prevented). Both maximum impact and high efficiency are desirable, but inherently in conflict and hard to compare.

The recently updated 2020 United States Preventative Services Task Force (USPSTF) eligibility criteria are: healthy individuals age 50-80 years, with a $\geq 20$-pack-year smoking history, either current smokers or having quit $\leq 15$ years ago (21). Increased smoking increases the risk of developing lung cancer, but also increases the risk of competing causes of death, the risk associated with biopsy and decreases the ability to undergo treatment due to co-morbidities. Modeling that accounts for both risk of developing lung cancer and life expectancy demonstrate that people with a higher risk of developing lung cancer have less mortality benefit due to already decreased life expectancy from comorbidities (13). Models also suggest that a life expectancy of 10 years is needed for lung cancer screening to have a high chance of benefit (13).

The current USPSTF and CHEST criteria recommend age 50 as the lower age threshold (instead of 55) $(13,21)$ based on several considerations. The CHEST meta-analysis demonstrated similar mortality reduction using age 50 or 55 (13); modeling studies suggest that while the risk of developing lung cancer at a younger age is less, the potential life years gained is similar, and that lowering age and smoking thresholds helps to extend screening to higher risk ethnic and racial groups better than the previous criteria $(13,21)$. There are some indications that the mortality reduction from screening is higher in women than in men $(5,6)$; however, there are too many confounders for this to result in gender-specific eligibility criteria.

Characteristics of the screening intervention are important. Mammography, for example, has evolved over several decades and specific training, quality control and certification is required. ACRIN has developed standards for LDCT screening for lung cancer (22). A low-dose and thin collimation scan is required; the report should be worded in a standardized manner specific to a screening CT. LungRADS or a similar categorization system should be used. The interval between screenings is crucial, as is the compliance. A single LDCT scan accomplishes little-it is the ongoing screening that decreases the incidence of latestage lung cancer and deaths.

The recent USPSTF and CHEST recommendations are annual screening until an individual no longer meets eligibility $(13,21)$. The CHEST meta-analysis found that biennial LDCT was associated with a similar lung cancer mortality benefit as annual screening, based on the MILD and NELSON RCTs $(5,9,12)$-but the stage shift in the NELSON trial suggests that the number of Stage IIIB/ IV cases increases (and stage I decreases) markedly with longer intervals (14). A longer interval accentuates the importance of compliance-but compliance with annual screening in screening programs has been much lower than in the RCTs ( $50 \% v s . \sim 90 \%)$ (23). Additionally, the phenomenon that screening detects excess cancers with very indolent biologic behavior is accentuated the longer the interval between screenings. Extensive modeling studies have consistently found that efficiency was better with annual than biennial screening (24). 


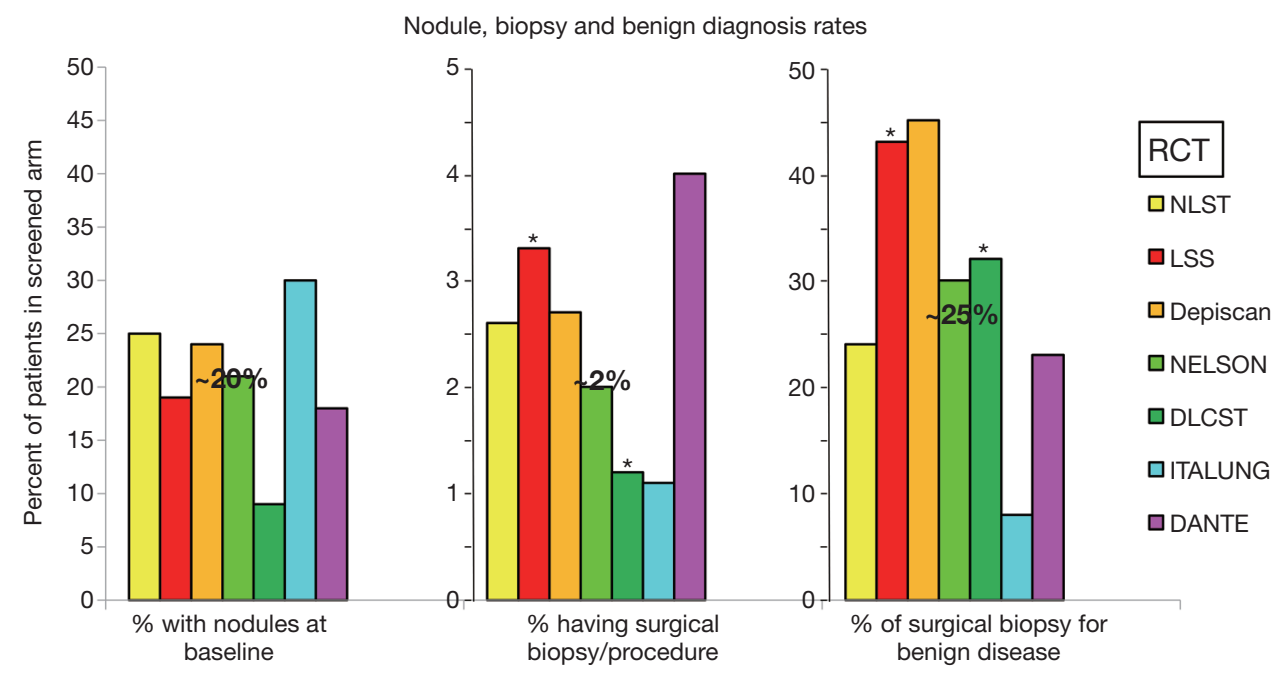

Figure 5 Nodule, biopsy, and benign diagnosis rates. Rates of screening-detected findings, surgical biopsy, and biopsies for a benign lesion in randomized trials of lung cancer screening. Data abstracted from a systematic review by Bach et al. (16). RCT, randomized controlled trial; NLST, National Lung Screening Trial; LSS, Lung Screening Study; NELSON, Nederlands-Leuvens Longkanker Screenings Onderzoek; DLCST, Danish Lung Cancer Screening Trial; DANTE, Detection and Screening of Early Lung Cancer by Novel Imaging Technology and Molecular Essays Trial. *, both surgical and non-surgical biopsies (i.e., needle aspiration) were reported together.

A

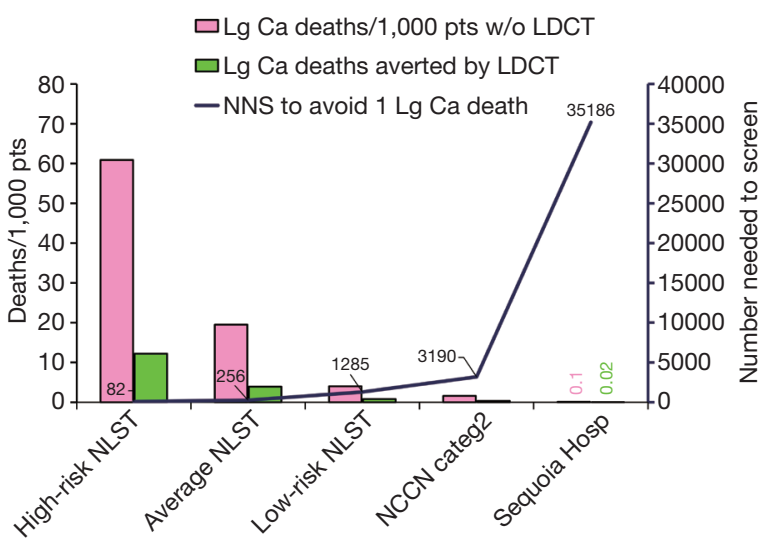

B Screened population vs. those with lung cancer and deaths averted

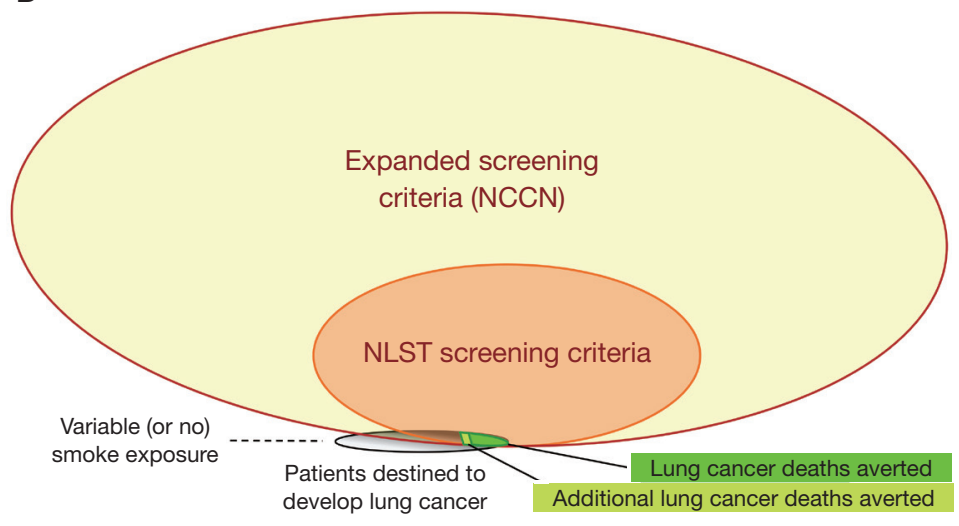

Figure 6 Relationship of risk, selectivity of who to screen and the impact on deaths averted. (A) Lung cancer, deaths and number needed to screen to avert on lung cancer death by risk criteria; (B) relationship between the populations screened, the number developing lung cancer, and deaths averted (drawn to approximate relative size). Data taken from Bach et al. and Tammemägi et al. (19,20). LDCT, lowdose computed tomography; NLST, National Lung Screening Trial; NNS, -needed to screen; NCCN, National Comprehensive Cancer Network.

These considerations contributed to the continued recommendation for an annual screening interval $(13,21)$.

\section{Discussion}

Screening involves a complex interplay of multiple factors.
It is important to be aware of several general principles of screening (which also apply to lung cancer). Screening involves a healthy population who are at risk of developing lung cancer, but only a small percentage will develop lung cancer. A huge benefit accrues to this small percentage, but all participants are exposed to potential downsides of 
Table 2 Key outcomes

Number of patients needed to screen to avert one lung cancer death: 300

Number patients needed to screen to cause unintended harm: 4,000

For every 10,000 patients screened that meet the NLST criteria:

- $\quad 30$ fewer people die of lung cancer (but 120 will still die from lung cancer)

- $\sim 2,000-3,000$ have a nodule detected (90\% of these are benign)

- $\quad 4$ experience a complication during work-up of a benign nodule (1 dies)

- $~ 3$ develop radiation-induced cancer (typically 10-20 years later)

NLST, National Lung Screening Trial.

screening. A one-time CT accomplishes little; ongoing regular screening makes the difference. Screening a narrow very-high risk population means more lives saved per number of screening tests, whereas screening a broad population increases the overall number of lung cancer deaths prevented. Trade-offs are inherently hard to balance (e.g., large benefit for a few $v s$. low risk of downsides for all, increased screening efficiency $v s$. larger number of deaths prevented). Screening inherently increases the proportion of indolent lung cancers; it is important not to overreact or overtreat.

There are also several issues that are specific to lung cancer screening with LDCT. Decades of experience in screening for other types of cancer has integrated these into general practice- this evolution is just beginning with lung cancer screening. It is hard to reach those at greatest risk (socio-economic factors, access, trust in the healthcare system, denial, fatalism) $(25,26)$. The process of lung cancer screening (risk assessment, shared decision-making) is more complex than for other cancer screenings. A screening CT has the potential to detect many non-lung findings (creating issues of how to manage, how to communicate these, who is responsible).

Lung cancer screening with LDCT has a huge potential to decrease deaths from the most common cause of cancer deaths. Key outcomes are summarized in Table 2. We have increasing RCT evidence that LDCT screening works. The challenge is to implement this so that we actualize the benefit that lung cancer screening provides.

\section{Conclusions}

Lung cancer is a major cause of death, largely because it is often not detected until late stage. Screening is associated with inherent issues, as well as additional challenges stemming from psychosocial aspects associated with smoking and the complexity of implementation of an organized lung cancer screening program. Other chapters in this series are devoted to many of these topics. This chapter reviews the evidence from RCTs that demonstrates a clear reduction in lung cancer mortality. We have increasing data regarding nuances of who to screen, how to manage screening findings. The time is clearly here to implement lung cancer screening in the fabric of healthcare.

\section{Acknowledgments}

Funding: None.

\section{Footnote}

Provenance and Peer Review: This article was commissioned by the Guest Editor (Sandra Starnes) for the series "Lung Cancer Screening" published in Current Challenges in Thoracic Surgery. The article has undergone external peer review.

Reporting Checklist: The authors have completed the Narrative Review reporting checklist. Available at https:// ccts.amegroups.com/article/view/10.21037/ccts-21-30/rc

Conflicts of Interest: All authors have completed the ICMJE uniform disclosure form (available at https://ccts. amegroups.com/article/view/10.21037/ccts-21-30/coif). The series "Lung Cancer Screening" was commissioned by the editorial office without any funding or sponsorship. The authors have no other conflicts of interest to declare.

Ethical Statement: The authors are accountable for all aspects for the work in ensuring that questions related to the accuracy or integrity of any part of the work are appropriately investigated and resolved. 
Open Access Statement: This is an Open Access article distributed in accordance with the Creative Commons Attribution-NonCommercial-NoDerivs 4.0 International License (CC BY-NC-ND 4.0), which permits the noncommercial replication and distribution of the article with the strict proviso that no changes or edits are made and the original work is properly cited (including links to both the formal publication through the relevant DOI and the license). See: https://creativecommons.org/licenses/by-nc-nd/4.0/.

\section{References}

1. Society AC. Key Statistics for Lung Cancer 2021. Available online: https://www.cancer.org/cancer/lungcancer/about/key-statistics.html\#: :text=Lifetime $\% 20$ chance $\% 20$ of $\% 20$ getting $\% 20$ lung,smokers $\% 20$ the $\% 20$ risk\%20is\%20lower

2. Peto R, Darby S, Deo H, et al. Smoking, smoking cessation, and lung cancer in the UK since 1950: combination of national statistics with two case-control studies. BMJ 2000;321:323-9.

3. Goldstraw P, Chansky K, Crowley J, et al. The IASLC Lung Cancer Staging Project: Proposals for Revision of the TNM Stage Groupings in the Forthcoming (Eighth) Edition of the TNM Classification for Lung Cancer. J Thorac Oncol 2016;11:39-51.

4. Oken MM, Hocking WG, Kvale PA, et al. Screening by chest radiograph and lung cancer mortality: the Prostate, Lung, Colorectal, and Ovarian (PLCO) randomized trial. JAMA 2011;306:1865-73.

5. National Lung Screening Trial Research Team; Aberle DR, Adams AM, et al. Reduced lung-cancer mortality with low-dose computed tomographic screening. N Engl J Med 2011;365:395-409.

6. de Koning HJ, van der Aalst CM, de Jong PA, et al. Reduced Lung-Cancer Mortality with Volume CT Screening in a Randomized Trial. N Engl J Med 2020;382:503-13.

7. Doroudi M, Pinsky PF, Marcus PM. Lung Cancer Mortality in the Lung Screening Study Feasibility Trial. JNCI Cancer Spectr 2018;2:pky042.

8. Paci E, Puliti D, Lopes Pegna A, et al. Mortality, survival and incidence rates in the ITALUNG randomised lung cancer screening trial. Thorax 2017;72:825-31.

9. Infante M, Cavuto S, Lutman FR, et al. Long-Term Follow-up Results of the DANTE Trial, a Randomized Study of Lung Cancer Screening with Spiral
Computed Tomography. Am J Respir Crit Care Med 2015;191:1166-75.

10. Pastorino U, Silva M, Sestini S, et al. Prolonged lung cancer screening reduced 10 -year mortality in the MILD trial: new confirmation of lung cancer screening efficacy. Ann Oncol 2019;30:1162-9.

11. Wille MM, Dirksen A, Ashraf H, et al. Results of the Randomized Danish Lung Cancer Screening Trial with Focus on High-Risk Profiling. Am J Respir Crit Care Med 2016;193:542-51.

12. Becker N, Motsch E, Trotter A, et al. Lung cancer mortality reduction by LDCT screening-Results from the randomized German LUSI trial. Int J Cancer 2020;146:1503-13.

13. Mazzone PJ, Silvestri GA, Patel S, et al. Screening for Lung Cancer: CHEST Guideline and Expert Panel Report. Chest 2018;153:954-85.

14. Yousaf-Khan U, van der Aalst C, de Jong PA, et al. Final screening round of the NELSON lung cancer screening trial: the effect of a 2.5 -year screening interval. Thorax 2017;72:48-56.

15. Detterbeck FC. Overdiagnosis during lung cancer screening: is it an overemphasised, underappreciated, or tangential issue? Thorax 2014;69:407-8.

16. Bach PB, Mirkin JN, Oliver TK, et al. Benefits and harms of CT screening for lung cancer: a systematic review. JAMA 2012;307:2418-29.

17. Detterbeck FC, Mazzone PJ, Naidich DP, et al. Screening for lung cancer: Diagnosis and management of lung cancer, 3 rd ed: American College of Chest Physicians evidence-based clinical practice guidelines. Chest 2013;143:e78S-e92S.

18. Lung CT Screening Reporting \& Data System (LungRADS). 2021. Available online: https://www.acr.org/ Clinical-Resources/Reporting-and-Data-Systems/ Lung-Rads

19. Bach PB, Gould MK. When the average applies to no one: personalized decision making about potential benefits of lung cancer screening. Ann Intern Med 2012;157:571-3.

20. Tammemägi MC, Katki HA, Hocking WG, et al. Selection criteria for lung-cancer screening. N Engl J Med 2013;368:728-36.

21. US Preventive Services Task Force; Krist AH, Davidson KW, et al. Screening for Lung Cancer: US Preventive Services Task Force Recommendation Statement. JAMA 2021;325:962-70.

22. Kazerooni EA, Armstrong MR, Amorosa JK, et al. 
ACR CT Accreditation Program and the Lung Cancer Screening Program Designation. J Am Coll Radiol 2016;13:R30-4.

23. Kaminetzky M, Milch HS, Shmukler A, et al. Effectiveness of Lung-RADS in Reducing FalsePositive Results in a Diverse, Underserved, Urban Lung Cancer Screening Cohort. J Am Coll Radiol 2019;16:419-26.

24. de Koning HJ, Meza R, Plevritis SK, et al. Benefits and harms of computed tomography lung cancer screening

doi: $10.21037 /$ ccts-21-30

Cite this article as: Mase VJ Jr, Kumbasar U, Detterbeck FC. The evidence behind lung cancer screening: a narrative review of randomized clinical trials. Curr Chall Thorac Surg 2023;5:8. strategies: a comparative modeling study for the U.S. Preventive Services Task Force. Ann Intern Med 2014;160:311-20.

25. Silvestri GA, Nietert PJ, Zoller J, et al. Attitudes towards screening for lung cancer among smokers and their nonsmoking counterparts. Thorax 2007;62:126-30.

26. Patel D, Akporobaro A, Chinyanganya N, et al. Attitudes to participation in a lung cancer screening trial: a qualitative study. Thorax 2012;67:418-25. 